\title{
Introduction to the Handbook (second edition): Comparative Sociological perspectives on racial and Ethnic Inequalities in Education
}

\section{Peter A. J. Stevens and A. Gary Dworkin}

This second edition of the Palgrave Handbook of Race and Ethnic Inequalities in Education brings together nearly forty years of sociological research on the relationship between race/ethnicity and educational inequality carried out in 25 national contexts. Not only does this second edition expand the number of countries examined, it also includes a chapter on cross-national comparative research on ethnic inequalities in education, using large-scale data-bases (such as PISA), an examination of the relationships among social cohesion, trust, and tolerance in each of the countries. Finally, the chapters report on the extent to which educational accountability systems impact education in the different nations. Such accountability systems are influenced by the forces of globalization and neoliberalism that heighten the competition among nations. An additional factor that impacted the present edition has been the growing refugee crises around the world, including those fomented by wars in the Middle East and changes in U.S. policies regarding immigrants and refugees that have resulted from the 2016 presidential election.

The development of the two editions of the Handbook were inspired by two earlier reviews from Stevens and colleagues on the relationship between race/ethnicity and educational inequality in England (Stevens 2007) and the Netherlands (Stevens et al. 2011). In conducting these reviews it became apparent that England and The Netherlands can fall back on rich traditions of research on this topic, but also that both bodies of literature are characterized by a focus on very different research questions and/or theoretical and methodological approaches. In addition, and somewhat in contradiction to what can be expected from a global, academic research community, scholars working in England and the Netherlands were mainly stimulated by national policy and research debates in developing and carrying out particular areas of research and less so by research conducted outside their national boundaries. The lack of mutual consideration and international cross-fertilization of research between these two (and other) countries, the abundance of research on race and ethnic inequalities in education and the lack of recent, more systematic and comprehensive reviews of literature in this area call for efforts to further investigate how different national contexts develop particular research traditions and findings and how they can learn from each other in further developing our knowledge of the relationship between race/ethnicity and educational inequality.

The two editions build on the two reviews published earlier by Stevens and colleagues in two ways. First, it expands the scope of these reviews by presenting the findings of research carried out on the relationship between race and ethnic inequality in eighteen different national contexts in the First Edition and 25 different national contexts in the Second Edition, including updated reviews of the articles written by Stevens and colleagues. In the Second Edition, these countries are purposively selected to cover a broad range of socio-economic and educational contexts and geographical regions throughout the world, including reviews of research in Africa (South Africa), Asia (China, Japan and Taiwan), Australia, Europe (Austria, Belgium, Cyprus, Czech Republic, England, France, 
Germany, Italy, Ireland, Norway, Sweden, Finland, The Netherlands), Euro-Asia (Russia and Turkey), North America (Canada and the USA), South America (Argentina and Brazil) and the Middle-East (Israel).

While the Anglo-Saxon countries included in this Handbook are well recognized in terms of the amount and importance of research carried out in relationship to race and ethnic inequalities in education, this is far less the case for the other countries included. This can in part be explained by the observation that research in these countries is often not written in English and/or does not find its way to high profile academic outlets. As a result, an important achievement of this book is that it offers a platform for this non-English research to be accessed and acknowledged by an English speaking academic community. In so doing, both editions of the Handbook pay tribute to and recognize the importance of the work conducted by many scholars throughout the world in developing knowledge on the relationship between race/ethnicity and educational inequality worldwide.

Second, each of the contributions included in the two edited books follow the same methodology in carrying out the review and structure in presenting the findings. Hence, while each national review can be read and stands on its own, the similarities in terms of methodology and structure between the chapters allow the reader to better compare the development of knowledge on the relationship between race/ethnic inequalities between different countries. More specifically, each chapter is similar in that they:

a) Offer a brief introduction of the characteristics of the educational system, the main migration processes and developments in terms of social policy in relationship to ethnic and racial inequality. This allows readers to better contextualize the findings of each review.

b) Are primarily concerned with identifying and critically reviewing the key research traditions that developed between 1980 and 2017 within their national context in relationship to research on race and ethnic inequalities in education. In line with Stevens (2007: 148), a research tradition is defined as: 'a set of studies developed over a certain period of time, which explore the relationship between educational inequality and race/ethnicity in a similar way by focusing on similar research questions, units of analysis, or social processes and use a similar set of research methods to achieve this goal'.

c) Are explicit about the employed sampling procedures, or which criteria of inclusion and databases were employed in developing a sample of literature to be reviewed, with the primary goal to be as comprehensive as possible. This transparency in terms of employed sampling frame helps the reader to better evaluate the focus and scope of the review.

While the international scope of the contributions and the similarities in terms of structure and methodology between the chapters contribute to the uniqueness of the two Handbooks and their relevance to the field, certain limitations need to be pointed out in advance. First, while most of the chapters in both editions of the Handbook are highly successful in offering a truly comprehensive review of the research literature that developed in their respective countries, there is unavoidably some variation between the chapters in terms of how comprehensive the reviews aim to be. Due to limitations in resources and/or the vast amount of literature written on this topic, some chapters necessarily restrict their focus on a smaller number of research traditions (e.g. chapter on the USA) and particular types of (for instance secondary) schooling (e.g. chapters on Ireland and the 
Netherlands). Furthermore, as it took over three years to develop this second edition of the Handbook, some chapters focus on the period 1980 - 2015, while others also cover research carried out more recently.

Secondly, in developing our conclusions, we as editors decided against writing a fully integrative review that is one that aims to bring together all the findings that emerged out of these studies into a single text and advises on future directions for research in each of the key research traditions and national contexts. As space limitations simply do not allow for such a review, the conclusions summarize some of the key characteristics of each national review (see for example the overview grid included in the concluding chapter) and point to main gaps in the literature. In so doing, this Second Edition of the Handbook does not only aim to map out how researchers have explained and studied race and ethnic inequalities in education and how future research can build on this, but it also functions as the most complete and comprehensive sourcebook to date on this topic, effectively allowing readers to carry out their own integrative reviews on particular topics by reading the conclusions of this Second Edition and critically summarizing particular sections of chapters. Furthermore, because of the various refugee crises affecting many nations, the concluding chapter also attempts to summarize how the influx of refugees and immigrants has impacted research on race and ethnic relations in terms of educational inequality in those countries and how such impacts have also affected societal cohesiveness in the various countries.

However, despite these shortcomings, we are adamant that, like the previous edition of the Handbook, this Second Edition offers a wealth of relevant information to students, researchers, social policy makers and activists interested in the relationship between race and ethnicity and educational inequalities. We hope that this book will encourage readers to investigate questions concerning inequality in education and society more generally from an international point of view, and consider the rich bodies of literature developed on this topic worldwide.

The focus on racial and ethnic inequality in education which is central to this handbook reflects a significant concern of the Sociology of Education Research Committee (known as RC04) of the International Sociological Association. The ISA, which was formally established in 1949, holds a charter from UNESCO and counts among its membership sociologists from 167 nations. As a professional organization, ISA holds membership in the International Council of Science. Its central office is in Madrid, Spain.

RCO4 has addressed issues of educational equity and access at most of the ISA's World Congresses and Forums held around the world since the RC's inception in 1971, then under the leadership of Pierre Bourdieu as president. Distinguished sociologists of education have held office in RCO4, including Basil Bernstein, Margaret Archer, the late Jaap Dronkers, Carlos Alberto Torres, Jeanne Ballantine, and Ari Antikainen. The editors and several of the contributors to this handbook are current members and even officers of RCO4. In fact, some of the chapters in this handbook originated as papers delivered at the 2010 World Congress of Sociology in Gotheburg, Sweden and the 2012 Second Forum of Sociology in Buenos Aires, Argentina.

Discussions with Palgrave regarding a Second Edition began late in 2015 and frequently involved emails and SKYPE calls between the editors. Over the past three years we have had numerous discussions between ourselves and with contributors to the second edition. In fact, we discussed expanding the number of countries covered during the 2014 World Congress of Sociology in 
Yokohama, Japan and met with contributors at the 2016 Third Forum of Sociology in Vienna, Austria. As with the previous edition, Peter Stevens took the lead in negotiations with Palgrave and in contacts with many of the original and new contributors.

In March 2016, Jaap Dronkers, former president of RCO4 and a contributor to the chapter on PISA and the use and misuse of international standardized tests, passed away suddenly. At the time of his death he was chair of International Comparative Research on Educational Performance and Social Inequality at the University of Maastricht. He previously had been a professor and dean of the faculty of education at the University of Amsterdam, Professor of Social Stratification and Inequality at the European University of Florence (EUI), and held an honorary doctorate from the University of Turku (Finland). RCO4 held a memorial for Jaap at our 2016 business meeting in Vienna, where several colleagues including contributors to this second edition spoke fondly of Jaap and his impact on the sociology of education and the understanding of the social structural forces that lead to racial and ethnic inequality. We remarked at the RCO4 meeting that "Jaap was an excellent researcher and scholar with a sharp mind, an extensive knowledge of the sociology of education, stratification and inequality, research methods, and world history. His sense of humour and smile were infectious. Google Scholar lists nearly 5,000 citations of his works and his C.V. identified hundreds of journal articles published in Dutch, English, German, and Spanish, as well as several hundred technical reports and policy papers. The European University Institute noted in his obituary that his books were '...quintessentially Jaap Dronkers: theoretically inspired, rich empirical work with a strong comparative focus. Jaap was an intellectual with a wide horizon who inspired several generations of younger scholars with his curiosity and enthusiasm.'”

He was a friend and colleague of many of us in RCO4, as well as contributors to this second edition, and he will be truly missed.

\section{Bibliography}

Stevens, Peter A. J. 2007. Researching Race/Ethnicity and Educational Inequality in English Secondary Schools: A Critical Review of the Research Literature Between 1980 and 2005. Review of Educational Research 77 (2): 147-185.

Stevens, Peter A. J., Noel Clycq, Christiane Timmerman, and Mieke Van Houtte. 2011. Researching Race/Ethnicity and Educational Inequality in the Netherlands: A Critical Review of the Research Literature between 1980 and 2008. British Educational Research Journal 37 (1): 543. 